OPEN ACCESS

Edited by:

Nick Gascoigne,

National University of Singapore,

Singapore

Reviewed by:

Tomasz Zal,

University of Texas MD Anderson

Cancer Center, USA

Jonathan Kaye,

Cedars-Sinai Medical Center, USA

*Correspondence:

Sudha Rao

sudha.rao@canberra.edu.au

Specialty section:

This article was submitted to T Cell

Biology, a section of the

journal Frontiers in Immunology

Received: 03 July 2015

Accepted: 21 October 2015

Published: 05 November 2015

Citation:

McCuaig RD, Dunn J, Li J, Masch A, Knaute T, Schutkowski M, Zerweck J

and Rao $S$ (2015) PKC-theta is a

novel SC35 splicing factor regulator in response to $T$ cell activation.

Front. Immunol. 6:562. doi: 10.3389/fimmu.2015.00562

\section{PKC-theta is a novel SC35 splicing factor regulator in response to $\mathrm{T}$ cell activation}

\author{
Robert Duncan McCuaig ${ }^{1}$, Jennifer Dunn ${ }^{1}$, Jasmine $L^{2}{ }^{2}$, Antonia Masch ${ }^{3}$, Tobias Knaute ${ }^{4}$, \\ Mike Schutkowski ${ }^{3}$, Johannes Zerweck ${ }^{4}$ and Sudha Rao ${ }^{1 *}$ \\ 'Discipline of Biomedical Sciences, Faculty of Education, Science, Technology and Maths, University of Canberra, Canberra, \\ ACT, Australia, ${ }^{2}$ Department of Microbiology and Immunology, The Doherty Institute for Infection and Immunity, University of \\ Melbourne, Melbourne, VIC, Australia, ${ }^{3}$ Department of Enzymology, Institute of Biochemistry and Biotechnology, Martin- \\ Luther-University, Halle, Germany, ${ }^{4}$ JPT Peptide Technologies GmbH, Berlin, Germany
}

Alternative splicing of nuclear pre-mRNA is essential for generating protein diversity and regulating gene expression. While many immunologically relevant genes undergo alternative splicing, the role of regulated splicing in T cell immune responses is largely unexplored, and the signaling pathways and splicing factors that regulate alternative splicing in T cells are poorly defined. Here, we show using a combination of Jurkat $T$ cells, human primary T cells, and ex vivo naïve and effector virus-specific T cells isolated after influenza A virus infection that SC35 phosphorylation is induced in response to stimulatory signals. We show that SC35 colocalizes with RNA polymerase II in activated T cells and spatially overlaps with $\mathrm{H} 3 \mathrm{~K} 27 \mathrm{ac}$ and $\mathrm{H} 3 \mathrm{~K} 4 \mathrm{me}$, which mark transcriptionally active genes. Interestingly, SC35 remains coupled to the active histone marks in the absence of continuing stimulatory signals. We show for the first time that nuclear PKC- $\theta$ co-exists with SC35 in the context of the chromatin template and is a key regulator of SC35 in T cells, directly phosphorylating SC35 peptide residues at RNA recognition motif and RS domains. Collectively, our findings suggest that nuclear PKC- $\theta$ is a novel regulator of the key splicing factor SC35 in T cells.

Keywords: SC35, PKC-theta, alternative splicing, T cells, histone marks, nuclear speckles

\section{INTRODUCTION}

Alternative splicing of nuclear pre-mRNA transcripts is an essential regulator of eukaryotic gene expression. Alternative splicing results in numerous functionally distinct protein isoforms from a single gene (1). Pre-mRNA splicing takes place within the spliceosome, a ribonucleoprotein complex enriched in pre-mRNA splicing machinery including small nuclear ribonucleoproteins (snRNPs), spliceosome subunits, non-snRNP splicing factors, and a plethora of unknown mRNA-regulating nuclear factors $(2,3)$. Upon target transcript binding at specific splice sites, spliceosomes catalyze the removal of non-coding introns and exon ligation to produce protein-coding mRNA. A number of mechanisms regulate alternative splicing of pre-mRNA, including exon skipping, intron retention, and the selective use of $3^{\prime}$ and $5^{\prime}$ splice sites (4). Alternative splicing is a key mechanism for generating protein diversity and regulating gene expression and, therefore, plays an important role in cell function and development. 
While most research has focused on transcriptional regulation of immune responses, alternative splicing of pre-mRNA is an emerging theme in the regulation of $\mathrm{T}$ cell function $(5,6)$. Several T cell genes, such as CD44 and CD45, undergo alternative splicing to produce distinct protein isoforms $(7,8)$. Furthermore, antigenic stimulation alters the pattern of alternative splicing to produce significant functional changes in protein expression $(8,9)$. Recent global studies of alternative splicing have identified a novel group of genes that undergo activation-induced alternative splicing in $\mathrm{T}$ cells. Many of these genes encode proteins that are important for $\mathrm{T}$ cell function, such as RNA-binding proteins and transcription factors $(10,11)$. However, although numerous immunologically relevant genes undergo alternative splicing, the role of alternative splicing in T cell memory remains largely unexplored.

SC35 (also known as SRSF2) is a well-characterized splicing factor that belongs to the serine/arginine-rich (SR) protein family, an important class of splicing regulators. SR proteins have a conserved structure characterized by one or two N-terminal RNA recognition motifs (RRMs) and a C-terminal arginine-serinerich (RS) domain that mediate RNA recognition and proteinprotein interactions within the spliceosome, respectively. SC35 is exclusively nuclear and, therefore, plays a key role in nuclear processes (12). In addition to its crucial function as an alternative splicing regulator, SC35 also participates in transcriptional elongation, RNA stability, mRNA transport, and translation (13, 14). Furthermore, human SC35 binds exonic splicing enhancers under splicing conditions (15).

SC35 is associated with alternative splicing in T cells. For example, SC35 regulates alternative splicing of the CD45 membrane receptor (16) and the cell adhesion molecule CD44 in T cells (17). Moreover, SC35 is aberrantly expressed in immune-related diseases, including SLE, leukemia, and HIV (18-20). SC35 alternative splicing also promotes the inclusion and accumulation of oncogenes, such as Ron and HPV16 $(21,22)$. Interestingly, SC35 dysregulation has been implicated in neurodegenerative diseases, suggesting that SC35 may mediate other memory processes, such as cognitive memory, in addition to immune responses (23). These studies collectively demonstrate SC35's important role in regulating immune responses to infections, but its role in $\mathrm{T}$ cell memory has not been examined.

Serine/arginine-rich splicing factors are phosphoproteins and are regulated by serine phosphorylation in the RS domain (23, 24). Several protein kinases have been shown to phosphorylate SR proteins (25), but the specifickinases that regulateSC35 in T cells are unknown. Several members of the protein kinase C (PKC) family, an evolutionarily conserved signaling kinase family, have been shown to regulate alternative splicing in many cell types including T cells $(8,26)$. Furthermore, both the PKC- $\alpha$ and PKC- $\delta$ isoforms have been shown to early-activate SC35 in post-natal rat cardiac muscle cells $(27,28)$. In T cells, PKC- $\theta$ is a central biochemical regulator that is essential for effective immune responses $(29,30)$. We have shown that PKC- $\theta$ is a novel nuclear epigenetic enzyme as well as a cytoplasmic signaling kinase. Nuclear-anchored PKC- $\theta$ forms an active signaling complex that directly binds to the promoter regions of inducible immune-responsive genes to regulate human T cell transcription (31). Given that several PKC family members have been shown to regulate alternative splicing events in T cells and that PKC- $\theta$ plays a key role in $\mathrm{T}$ cell function, we hypothesize that PKC- $\theta$ regulates SC 35 in T cells.

Using a combination of Jurkat $\mathrm{T}$ cells, human primary $\mathrm{T}$ cells, and ex vivo naïve and effector virus-specific $\mathrm{T}$ cells isolated after influenza A virus infection, we show that SC35 phosphorylation (SC35p) is induced in response to stimulatory signals. Specifically, SC35p colocalizes with RNA polymerase II activated $\mathrm{T}$ cells and closely associates with $\mathrm{H} 3 \mathrm{~K} 27 \mathrm{ac}$ (an active enhancer mark) and H3K4me3 (a promoter mark), which mark transcriptionally active genes. Interestingly, SC35 remains coupled to the active histone marks in the absence of continuing stimulatory signals. We show for the first time that nuclear PKC- $\theta$ co-exists with SC35 in the context of the chromatin template and is a key regulator of SC35 in T cells, directly phosphorylating SC35 peptide residues at RRM and RS domains. Collectively, our findings suggest that nuclear PKC- $\theta$ is a novel regulator of the key splicing factor SC35 in T cells.

\section{MATERIALS AND METHODS}

\section{Jurkat T Cell Culture}

The Jurkat stimulation model was used as previously described (32). The human Jurkat T cell line (Clone E6-1, ATCC ${ }^{\circledR}$ TIB152) was cultured in complete $10 \%$ fetal bovine serum (FBS) RPMI media (Gibco, Life Technologies, Carlsbad, CA, USA). Jurkat $\mathrm{T}$ cells were either not stimulated (NS) or activated (ST) for $2 \mathrm{~h}$ at $5 \times 10^{5}$ cells $/ \mathrm{mL}$ with $24 \mathrm{ng} / \mathrm{mL}$ phorbol 12 -myristate 13-acetate (PMA; Sigma-Aldrich, St. Louis, MO, USA; P8139) and $1 \mu \mathrm{M}$ calcium ionophore (I; Sigma-Aldrich, A23187). For the stimulation model, previously activated Jurkat $\mathrm{T}$ cells were washed five times with stimulus-free medium and re-cultured for 3 days (SW) and subsequently re-stimulated (RST). For inhibitor studies, cells were pre-treated with rottlerin (Calbiochem) for $1 \mathrm{~h}$ prior to activation $(31,33)$.

\section{PKC- $\theta$ and Plasmid Transfections}

Two full-length PKC- $\theta$ gene sequence constructs were used to create two plasmids with active or inactive nuclear localization: wild-type PKC- $\theta$ (PKC $\theta$ WT) or a PKC- $\theta$ gene sequence in which the non-canonical NLS sequence was inactivated by mutation (PKCO NLS) as previously (34). Briefly, these sequences were cloned into the pTracer-CMV vector in frame with a C-terminal HA tag. Jurkat T cells were transiently transfected with $15 \mu \mathrm{g}$ of vector-only plasmid, HA-tagged wild-type PKC- $\theta$, or cytoplasmicrestricted PKC- $\theta$ plasmid using the NEON Transfection System Kit (Invitrogen, Life Technologies; MPK5000). Cells were subsequently stimulated as per the Jurkat stimulation model described above and fixed $48 \mathrm{~h}$ later in $2 \%$ formaldehyde and centrifuged onto poly-L-lysine-coated coverslips.

\section{Immunofluorescence/Image Acquisition}

Coverslips of $\mathrm{T}$ cells were permeabilized by incubation with $1 \%$ Triton X-100 for $20 \mathrm{~min}$ and probed with a mouse antibody to phospho-epitopes of human SC35p (Abcam, Cambridge, UK; ab11826) followed by a secondary goat antibody to mouse AlexaFluor 568 (Lifetech A-10037). To examine colocalization, T cells were probed with an antibody mix of primary mouse antibody 
to SC35 with rabbit-raised antibodies targeting either human RNA-Pol-II-ser2p (Abcam ab5095), H3K4me3 (Merck 07-473), H3K27ac (Abcam ab4729), or PKC- $\theta$ (Abcam AB63365) followed by visualization with a secondary goat antibody to mouse immunoglobulins conjugated to Alexa-Fluor 568 and secondary antibodies to rabbit immunoglobulins conjugated to Alexa-Fluor 488 (Lifetech A-11008), respectively.

Coverslips were subsequently mounted on glass microscope slides with ProLong Gold anti-fade reagent (Life Technologies). Confocal laser scanning microscopy was used to study SC35 localization as previously described (35). $0.5 \mu \mathrm{m}$-spaced images were obtained with a Nikon x60 oil immersion lens on a Nikon C1 plus confocal system using NIS-Elements AR 3.2 software. The final image was obtained by averaging four sequential images from the same section at high resolution.

\section{Microscopy Data Analysis}

Digital confocal images of PKC- $\theta$ were analyzed using the FijiImageJ software (36) to determine the nuclear to cytoplasmic fluorescence ratio $(\mathrm{Fn} / \mathrm{c})$ using the equation: $\mathrm{Fn} / \mathrm{c}=(\mathrm{Fn}-\mathrm{Fb}) /$ $(\mathrm{Fc}-\mathrm{Fb})$, where $\mathrm{Fn}$ is nuclear fluorescence, $\mathrm{Fc}$ is cytoplasmic fluorescence, and $\mathrm{Fb}$ is background fluorescence. A minimum of $N=20$ cells were analyzed for each sample set. SC35 nuclear speckles were analyzed using Fiji-ImageJ software, with the nucleus of each cell and total nuclear fluorescence computed by the software. The Mann-Whitney non-parametric test (GraphPad Prism, GraphPad Software, San Diego, CA, USA) was used to determine significant differences between datasets.

\section{Microscopy Colocalization Analysis}

For visualization of colocalization of confocal images, different image channels were overlaid in the same $Z$-plane. Consequently, a green and red overlay gave rise to yellow hotspots where the two molecules of interest were present in the same pixel locations. Statistical analysis of colocalization was performed with an intensity correlation coefficient-based method using the Colo-2 Fiji-ImageJ plugin with automatic thresholding (36-38). Pearson's colocalization coefficients (PCCs) were collected using the ROI manager to select at least 20 individual nuclei per sample set. PCC could range from 1 to -1 , with 1 denoting complete positive correlation, -1 complete negative correlation, and 0 no correlation. Data were presented as mean \pm SEM. Statistical analyses were performed with Student's $t$-test for paired comparisons. Additionally the Plot-Profile feature of Fiji-ImageJ was used to record the fluorescence intensity of a pair of antibody targets along a line through selected SC35 speckles. For each dataset, three speckles were counted for three separate cells and plotted with the mean \pm SEM.

\section{Immunoblot Analysis}

Immunoblot analysis was performed using primary mouse antibody to human SC35p (as above, ab11826) and secondary HRP-conjugated goat-anti-mouse antibody on nuclear extracts isolated from either primary human $\mathrm{CD}^{+}$cells, which were untreated (mock) or treated with Life Technologies siRNA PKC- $\theta$ pool (Life Technologies ID s11122, s11123), PKC- $\theta$ siRNA (Santa Cruz SC-36252), or nuclear extracts from NS or ST Jurkat T cells either untreated or treated with rottlerin. Nuclear extracts of transfected Jurkat $\mathrm{T}$ cells were also probed for nuclear expression of HA-tagged PKC- $\theta$ WT or NLS mutant constructs using a primary rabbit antibody to HA (Sigma, H6908). Signals were detected with enhanced chemiluminescence reagents (Western Lightning ECLPlus, Perkin-Elmer NEL104001) and film exposure. Band intensity signals were normalized to the total protein transferred to the blot detected using the Quantitative Novex Reversible Protein Stain (Thermo Fisher Scientific IB7710) and Image J analysis.

\section{Half-Way ChIP Assays}

Half-ChIP assays were performed according to the manufacturer's instructions (Upstate Biotechnology) and as previously described for Jurkat T cells (31). Fixation was performed as detailed, and fixed chromatin was sonicated with an Ultrasonic processor (Qsonica) under optimized conditions to produce average DNA fragments of $\sim 500 \mathrm{bp}$. Prior to antibody addition, samples were pre-cleared with salmon sperm DNA-protein A-agarose, and the soluble chromatin fraction was incubated overnight at $4^{\circ} \mathrm{C}$ with a primary antibody to PKC- $\theta$ and Protein A magnetic beads. The beads were washed and incubated with immunoblot loading buffer containing beta-mercaptoethanol at $95^{\circ} \mathrm{C}$ and analyzed as above (Immunoblot analysis) with a primary SC35 antibody.

\section{Kinase Profiling on Peptide Microarrays}

Active recombinant PKC- $\theta$ was provided to JPT Peptide Technologies (Berlin, Germany) for kinase profiling on peptide microarrays. Unmodified SC35 peptides were chemoselectively immobilized on glass slides and incubated with kinase solution in the presence of $\gamma-{ }^{33} \mathrm{P}$-ATP prior to high-resolution phosphorimaging. Spot recognition software packages, GenepixPro 7.2 and ArrayPro 4.0, were used for data analysis. Peptide constructs that displayed a normalized mean signal equal to or greater than two SDs above the mean were considered likely positive for phosphorylation events. Excel, R, and Python were used to determine the statistical significance of sequences and phosphorylation events.

\section{Total RNA Isolation and Quantitative Real-Time PCR}

Total RNA was extracted and reverse transcription qPCR was performed as previously described (39) using the Maxima FirstStrand cDNA Synthesis Kit (Thermo Scientific, Waltham, MA, USA) and 1:20 dilutions of cDNA for the RT-qPCR reaction. $\mathrm{Ct}$ values were normalized to the housekeeping gene GAPDH. Data were expressed as fold changes in message relative to NS. The following human TaqMan primer sets were used: SC35 Hs01923929_s1 (Life Technologies), GAPDH Hs99999905 (Life Technologies).

\section{RESULTS}

\section{SC35p Is Induced in Ex Vivo-Derived Effectors Compared to Naïve T Cells in Response to Viral Infection}

Given that the splicing factor SC35 regulates alternative splicing in $\mathrm{T}$ cells, we initially determined the subcellular distribution of SC35 by fluorescence microscopy in the human Jurkat T cell 
line; cells were either non-stimulated or stimulated with phorbolmyristate acetate and calcium ionophore (PMA/I), a known PKC pathway inducer. The phosphorylated epitope of SC35 (SC35p) was detected. Immunofluorescence analysis showed that the total nuclear fluorescence of SC35p was substantially increased following primary stimulation compared to non-stimulated Jurkat $\mathrm{T}$ cells (Figure 1A).

We next investigated SC35p dynamics in naïve and effector T cells utilizing an established virus infection model in which naive $\left(\mathrm{CD} 44^{\mathrm{lo}} \mathrm{CD} 62 \mathrm{~L}^{\text {hi }}\right)$ OT-I TCR transgenic CD8 ${ }^{+} \mathrm{T}$ cells specific for the ovalbumin peptide (OVA257-264) were adoptively transferred into congenic $\mathrm{C} 57 \mathrm{BL} / 6 \mathrm{~J}$ (B6) hosts followed by intranasal (i.n.) infection with the A/HKx31-OVA virus (40). Immunofluorescence analysis of sort-purified ( $>99 \%$ purity, Figures S1A,B in Supplementary Material) naive (day 0) and effector (day 10) $\mathrm{T}$ cells was performed. Consistent with the activated Jurkat $\mathrm{T}$ cells, SC35p was markedly increased in virus-specific effector $\mathrm{T}$ cells compared to naïve $\mathrm{T}$ cells (Figure 1B). Overall, our findings suggest that SC35p is induced in a stimulus-dependent manner in both the Jurkat T cell line and virus-specific T cells.

\section{SC35p Spatially Overlaps with Active Histone Marks in Effector T Cells in Response to Viral Infection}

Highly compacted chromatin structures enriched in nucleosomes are transcriptionally silent. Chromatin accessibility is pivotal in regulating gene expression and can be orchestrated via a number of mechanisms including the addition of PTMs to histone proteins (41-43). To determine if SC35p localizes to transcriptionally active genes during $\mathrm{T}$ cell differentiation in response to infection, we double-stained with SC35p and histone H3K27ac (Figure 1C), H3K4me3 (Figure 1D), or RNA polymerase II-serine2 phosphorylation (Figure 1E), which are associated with transcriptionally active or poised genes $(44,45)$ in naïve (day 0) and effector (day 10) OT1 CTLs. SC35p was strongly colocalized with all three active marks after differentiation into effector CTLs: PCC $0.65 \pm 0.01 \mathrm{H} 3 \mathrm{k} 27 \mathrm{ac}$ (C); PCC $0.62 \pm 0.01$ H3k4me3 (D); PCC $0.64 \pm 0.03$ RNA polymerase II-serine2 (E). These findings suggest that SC $35 \mathrm{p}$ co-exists within key regulatory regions strongly linked with active enhancers $(\mathrm{H} 3 \mathrm{~K} 27 \mathrm{ac})$ and gene promoter regions ( $\mathrm{H} 3 \mathrm{~K} 4 \mathrm{me} 3$ ) in the context of virus-specific CTL differentiation.

\section{SC35p Remains Localized to Active Histone Marks in the Absence of Continuous T Cell Activation Signals}

Nuclear accumulation of SC35p correlates with active transcription. To assess the time-dependency of nuclear SC35p after continuous $\mathrm{T}$ cell activation, an experiment was designed (see schematic, Figure S2A in Supplementary Material) to measure SC35p and its ability to colocalize with active PTMs before (NS), during (ST), and after (cells were washed five times to remove stimulus and maintained for three divisions; SW) T cell activation or after RST. Double staining with the active transcription marks H3K27ac (Figure 2A), H3K4me3 (Figure 2B), and RNA Pol II (Figure 2C) indicated that SC35p strongly colocalized with all three histone marks in both primary stimulation (ST) (Figures 2A-C; PCC $0.66 \pm 0.02 \mathrm{H} 3 \mathrm{k} 27 \mathrm{ac}$; PCC $0.72 \pm 0.017$ H3k4me3; PCC $0.7 \pm 0.01$ RNA Pol II-ser2) and secondary (RST) stimulation conditions (Figures 2A-C; PCC $0.72 \pm 0.019$ $\mathrm{H} 3 \mathrm{k} 27 \mathrm{ac}$; PCC $0.67 \pm 0.01 \mathrm{H} 3 \mathrm{k} 4 \mathrm{me} 3$; PCC $0.76 \pm 0.01 \mathrm{RNA}$ Pol II-ser2). Interestingly, this favorable colocalization was also observed in the absence of ongoing stimulation in SW Jurkat cells (Figures 2A-C PCC 0.0.54 \pm 0.016 H3k27ac; PCC $0.46 \pm 0.03 \mathrm{H} 3 \mathrm{k} 4 \mathrm{me} 3$; PCC $0.71 \pm 0.02 \mathrm{RNA}$ Pol II-ser2). In contrast, no colocalization of these active transcription marks was observed in NS Jurkat T cells. Thus, SC35p is induced following primary activation and is maintained with active chromatin marks after stimulus withdrawal and further induced following secondary stimulation. It should be noted that SC35 gene expression was unchanged under all conditions (Figures S3A,B in Supplementary Material). These data suggest that primary stimulation is required for induction of SC35 phosphorylation and for its co-existence with active chromatin marks and this association with chromatin is maintained in the absence of continued activation signals.

\section{PKC- $\theta$ Regulates SC35p in Activated T Cells}

Several protein kinases capable of phosphorylating SR proteins have been described $(23,24,27,28)$. However, the specific SC35regulating kinases in $\mathrm{T}$ cells have yet to be identified. Given that $\mathrm{PKC}-\theta$ is a critical regulator of gene expression in human T cells $(29,30)$, we speculated that PKC- $\theta$ might also regulate SC35 expression in Jurkat T cells. Double staining and confocal microscopy revealed strong colocalization of PKC- $\theta$ and SC $35 \mathrm{p}$ in viral influenza-specific OT-1 CD8 ${ }^{+}$effector T cells (Figure 3A; PCC $0.64 \pm 0.013)$. In contrast, no colocalization was detected in naive OT-1 T cells (Figure 3A, PCC $0.06 \pm 0.07$ ). Next, we investigated the impact of PKC- $\theta$ knockdown on SC35p by immunoblotting with anti-SC35p in either mock or PKC- $\theta$ siRNA1 (Lifetech) and siRNA2 (Santa Cruz)-treated nuclear extracts of primary human bulk CD4 ${ }^{+} \mathrm{T}$ cells. Both siRNA pools substantially inhibited SC35 phosphorylation relative to the mock treatment (Figure 3B).

Next, weassessed theimpactofPKC- $\theta$ catalyticactivityonSC35p. PKC- $\theta$ catalytic activity is necessary for chromatin association and inducible gene expression (31). To assess the impact of PKC- $\theta$ catalytic activity, we used an ATP-competitive PKC- $\theta$ inhibitor, which has previously shown to inhibit PKC- $\theta$ activity in human $\mathrm{T}$ cells $(31,33)$. Immunoblotting for SC35p in rottlerin or vehicle pre-treated NS and ST Jurkat T cell nuclear extracts displayed a significant reduction in SC35p phosphorylation compared to the mock-treated cells. Collectively, these data indicate a role for PKC- $\theta$ kinase activity in the active phosphorylation of SC35 in T cells (Figure 3C).

\section{Nuclear PKC-Theta and SC35p Co-exist in Jurkat T Cells}

We have previously shown that $\mathrm{PKC}-\theta$ can function as a nuclear epigenetic enzyme in $\mathrm{T}$ cells as well as a cytoplasmic signaling kinase (31). To distinguish the cytoplasmic and nuclear roles 

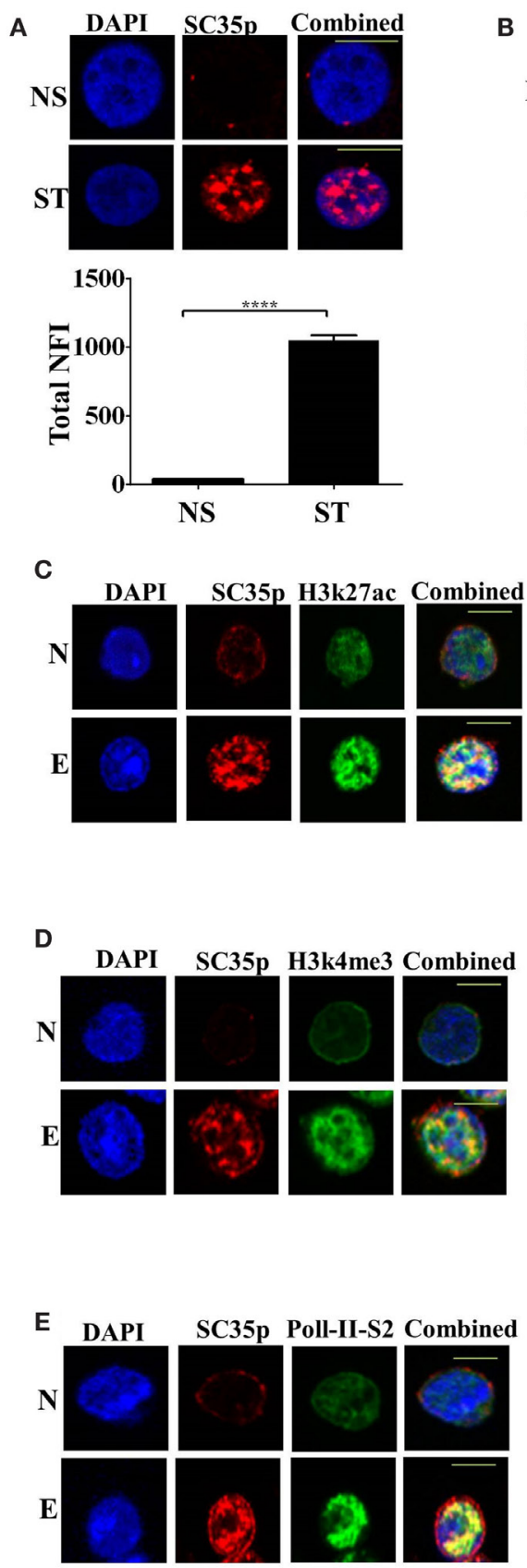

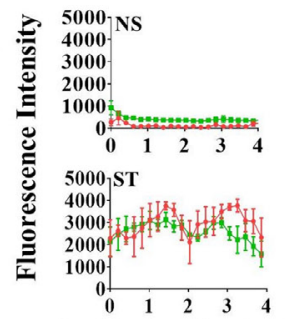

Position on line $(\mu \mathrm{m})$

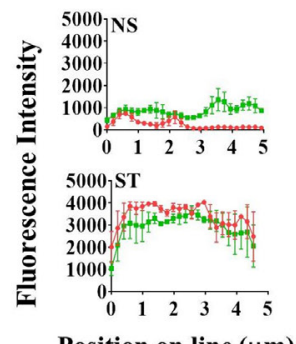

Position on line $(\mu \mathrm{m})$
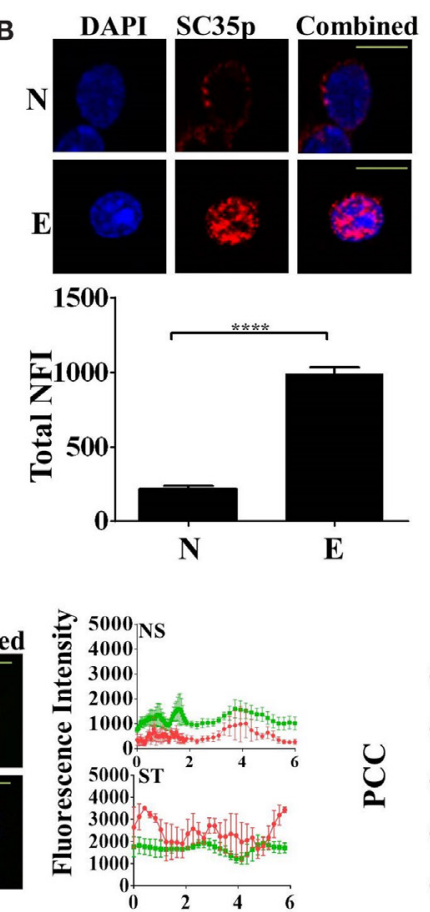

Position on line $(\mu \mathrm{m})$
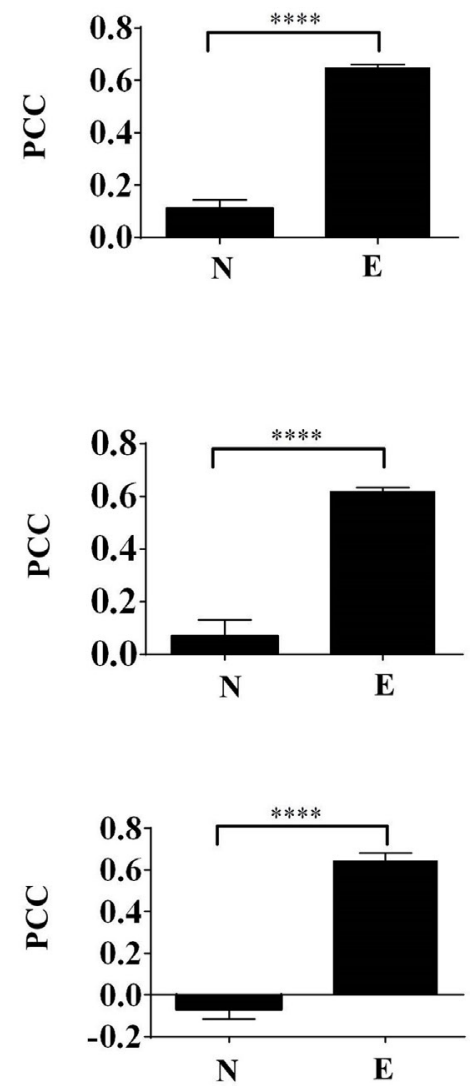

FIGURE 1 | Expression of phosphorylated SC35 in T cells and in primary mouse OT-1 T cells. (A) Jurkat T cells were either unstimulated (NS) or PMA/l-activated (ST) for $2 \mathrm{~h}$ or (B) naive OT-1 CD8 ${ }^{+}$CD44//intermediate T-cells or influenza-specific effector OT-1 CD8 ${ }^{+} \mathrm{T}$ cells were fixed and probed with a mouse antibody to a phospho-epitope of SC35 followed by visualization with a secondary goat antibody to mouse immunoglobulins conjugated to Alexa-Fluor 568 . Confocal laser scanning microscopy was used to measure SC35 expression as detailed in the section "Materials and Methods." Representative images for each treatment are shown, with a 10- $\mu \mathrm{m}$ scale bar for (A) and a 5- $\mu \mathrm{m}$ scale bar for (B). Total nuclear fluorescence intensity (NFI) was measured with Fiji-ImageJ. Data represent the mean \pm SEM, $n=20$ for each dataset with significant differences between datasets indicated. Naive OT-1 CD8 ${ }^{+}$CD44/intermediate T-cells or influenzaspecific effector OT-1 CD8 ${ }^{+}$T cells were fixed and probed with a primary mouse antibody to a phospho-epitope of human SC35 and primary rabbit antibody to H3K27ac (C), H3K4me3 (D), or RNA-Pol-II ser-2 phosphorylation (E) followed by visualization with a secondary goat antibody to mouse immunoglobulins conjugated to Alexa-Fluor 568 and secondary antibodies to rabbit immunoglobulins conjugated to Alexa-Fluor 488, respectively. Confocal laser scanning microscopy was used to measure expression of SC35 and H3K27ac, H3k4me3, or RNA-Pol-II ser-2 as described in the section "Materials and Methods." Representative images for each treatment are shown with a 5- $\mu \mathrm{m}$ scale bar. Channels were overlaid to examine colocalization of the antibody targets. Pearson's colocalization coefficient (PCC) and mean fluorescent intensity line scans were calculated with Fiji-ImageJ as described in the section "Materials and Methods." Data represent the mean $\pm \mathrm{SEM}, n=20$ for each dataset with significant differences between datasets indicated. Red = SC35p; green = H3K27ac, H3k4me3, or RNA-Pol-II-ser2; and yellow = visual overlap between the fluorescence signals. 

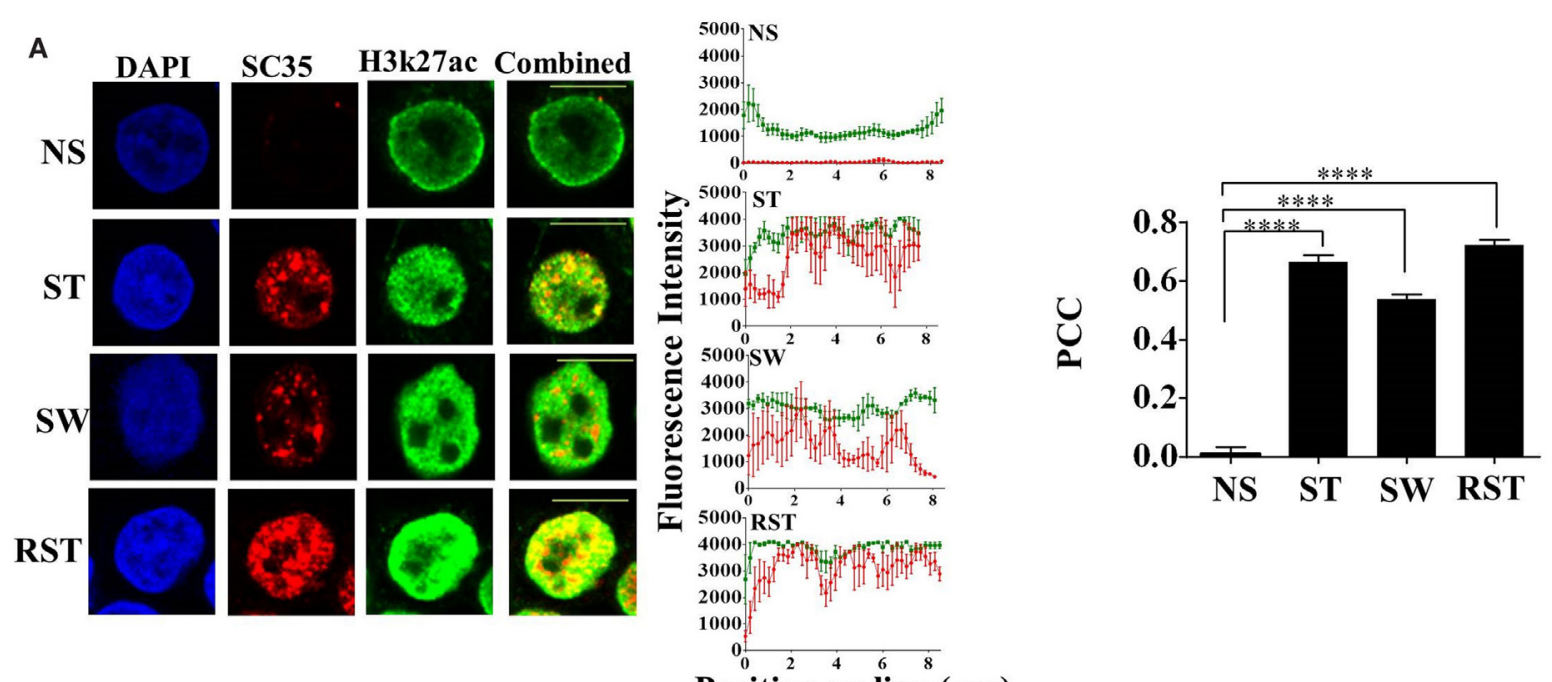

Position on line $(\mu \mathrm{m})$
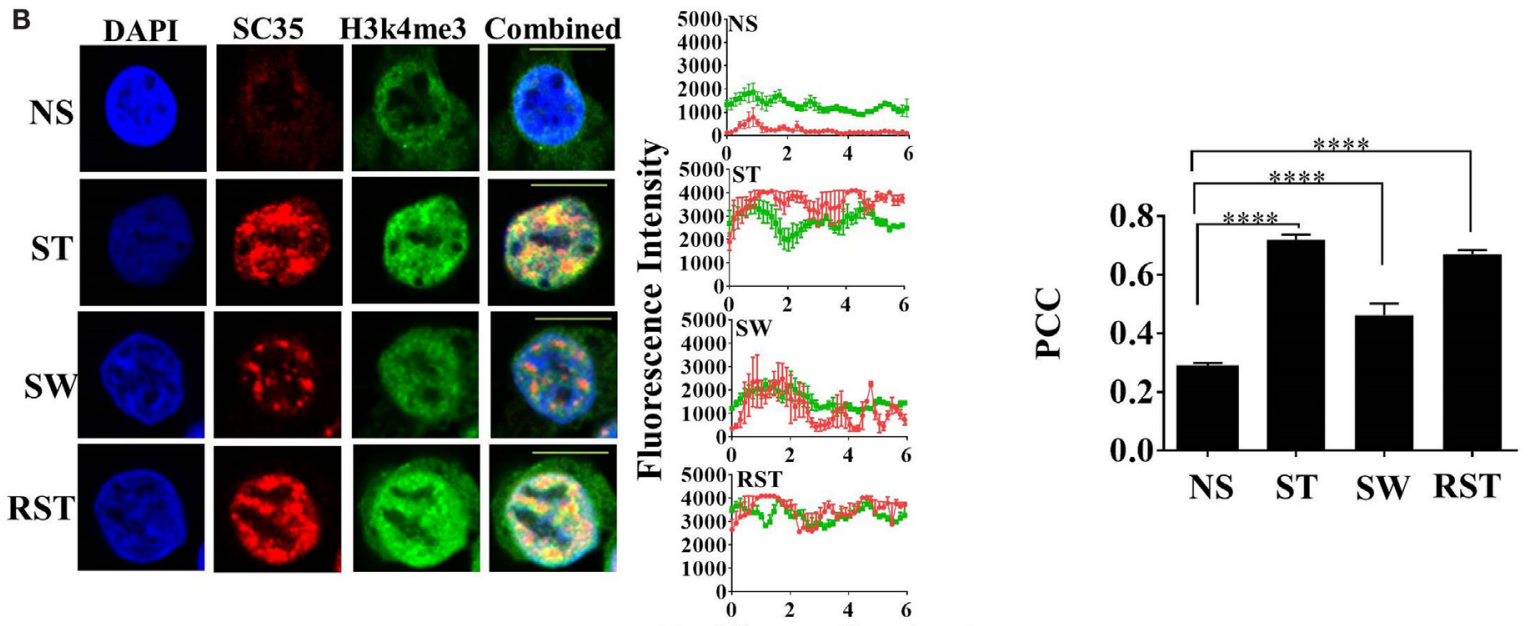

Position on line $(\mu \mathrm{m})$
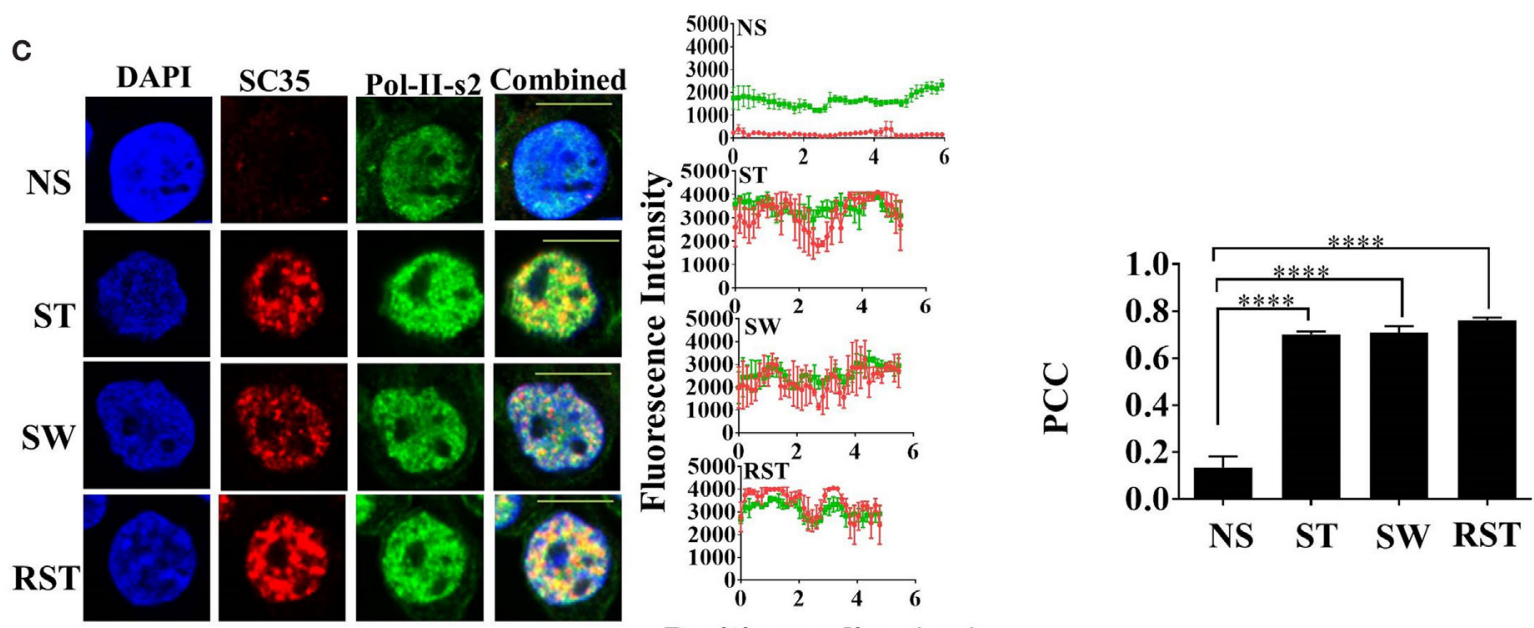

Position on line $(\mu \mathrm{m})$

FIGURE 2 | Interplay between SC35p, histone PTMs, and RNA-Pol-II ser2 in the Jurkat T cell model 


\section{FIGURE 2 | Continued}

Jurkat T cells stimulated as described in the section "Materials and Methods" (NS, no stimulation; ST, stimulation; SW, stimulus withdrawal; RST, re-stimulation) were fixed and probed with a primary mouse antibody to a phospho-epitope of human SC35 and primary rabbit antibody to H3K27ac (A), H3K4me3 (B), or RNA-Pol-II ser-2 (C) followed by visualization with a secondary goat antibody to mouse immunoglobulins conjugated to Alexa-Fluor 568 and secondary antibodies to rabbit immunoglobulins conjugated to Alexa-Fluor 488, respectively. Confocal laser scanning microscopy was used to measure expression of SC35p and H3K27ac, H3k4me3, or RNA-Pol-II-ser-2. Representative images for each stimulation point are shown with a 10- $\mu$ m scale bar. Channels were overlaid to examine colocalization of the antibody targets. Pearson's co-localizaton coefficient (PCC) and mean fluorescent intensity line scans were calculated with Fiji-ImageJ as described in the section "Materials and Methods." Data represent the mean \pm SEM, $n=20$ for each dataset with significant differences between datasets indicated. Red = SC35; green = H3K27ac, H3k4me3, or RNA-Pol-II-ser2; and yellow = visual overlap between the fluorescence signals.
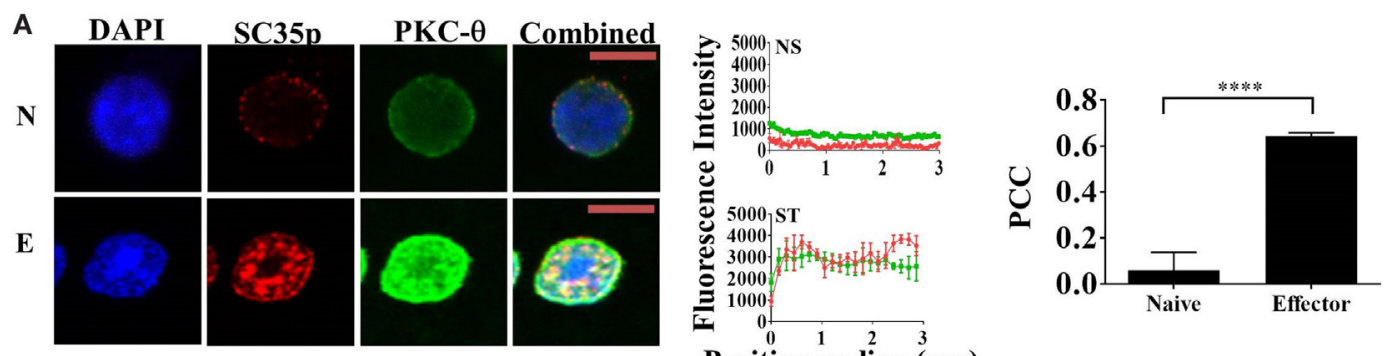

Position on line $(\mu \mathrm{m})$
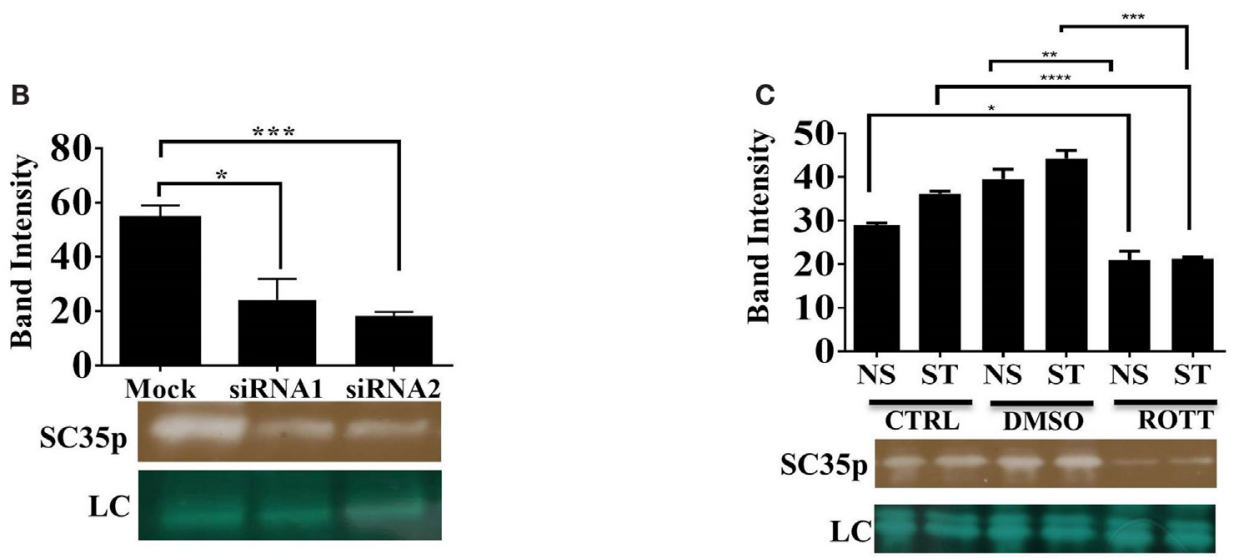

FIGURE 3 | Interplay between PKC- $\boldsymbol{\theta}$ and SC35 phosphorylation. (A) Naive OT-1 CD8 ${ }^{+}$CD44/o/intermediate $T$-cells or influenza-specific effector OT-1 CD8 ${ }^{+}$T-cells were fixed and probed with a primary mouse antibody to a phospho-epitope of SC35 and primary rabbit antibody to PKC- $\theta$ followed by visualization with a secondary goat antibody to mouse immunoglobulins conjugated to Alexa-Fluor 568 and secondary antibodies to rabbit immunoglobulins conjugated to Alexa-Fluor 488, respectively. Confocal laser scanning microscopy was used to measure expression of SC35 and PKC- $\theta$. Representative images for each stimulation point are shown with a $5-\mu \mathrm{m}$ scale bar. Channels were overlaid to examine colocalization of the antibody targets. Pearson's colocalization coefficient (PCC) and mean fluorescent intensity line scans were calculated with Fiji-ImageJ as described in the section "Materials and Methods." Data represent the mean \pm SEM, $n=20$ for each dataset with significant differences between datasets indicated. Red = SC35; green = PKC- $\theta$; and yellow = visual overlap between the fluorescence signals. (B) Cell lysates of primary human CD4+ cells were untreated (mock) or treated with PKC- $\theta$ siRNA1 (Life Technologies) or siRNA2 (Santa Cruz). Effect on SC35 was analyzed by immunoblotting with a mouse raised primary antibody to a phospho-epitope of SC35, measuring band intensity with Fiji-Image J for each sample. A representative image of SC35 labeling for three separate experiments $(n=3)$ is displayed (labeled SC35), with the mean intensity plotted with significant differences displayed for each treatment along with a representative loading control (LC) as described in the section "Materials and Methods." The effect of rottlerin treatment (C), a PKC- $\theta$-specific kinase inhibitor, on SC35 phosphorylation was also examined by immunoblotting as described above. A representative loading control (LC) is shown along with a representative SC35p-probed blot for three separate experiments $(n=3)$. The mean intensity is plotted with significant differences displayed for each treatment.

of PKC- $\theta$ in SC35p expression, previously validated PKC- $\theta$ constructs (34), a HA tagged wild-type PKC- $\theta$ (HA PKC- $\theta$ WT) or a HA tagged PKC- $\theta$ with a mutated NLS ( ${ }^{\mathrm{HA}} \mathrm{PKC}-\theta$ NLS), were expressed in Jurkat $\mathrm{T}$ cells. Consistent with our previous observations, ${ }^{\text {HAPKC- } \theta}$ NLS was significantly cytoplasmic restricted compared to the ${ }^{\mathrm{HA}} \mathrm{PKC}-\theta$ WT in the Jurkat and HUT $\mathrm{T}$ cell lines (Figures $\mathbf{4 A - C}$ ). Next, to determine the effect of nuclear PKC- $\theta$ regulation on SC35 phosphorylation in Jurkat T cells, the subcellular distribution of SC35p was analyzed in Jurkat $\mathrm{T}$ cells transfected with vector-only (mock) control and PKC- $\theta$ plasmid constructs and then stimulated $48 \mathrm{~h}$ after transfection in the Jurkat stimulation model. Total nuclear SC35p fluorescence significantly increased in all ${ }^{\mathrm{HA}} \mathrm{PKC}-\theta \mathrm{WT}$-treated cells (Figure 4E) overexpressing PKC- $\theta$ compared to mock constructs (Figure 4D), suggesting that $\mathrm{PKC}-\theta$ plays a role in speckle formation. In contrast, transfection with the ${ }^{\mathrm{HA}} \mathrm{PKC}-\theta$ NLS mutant resulted in 

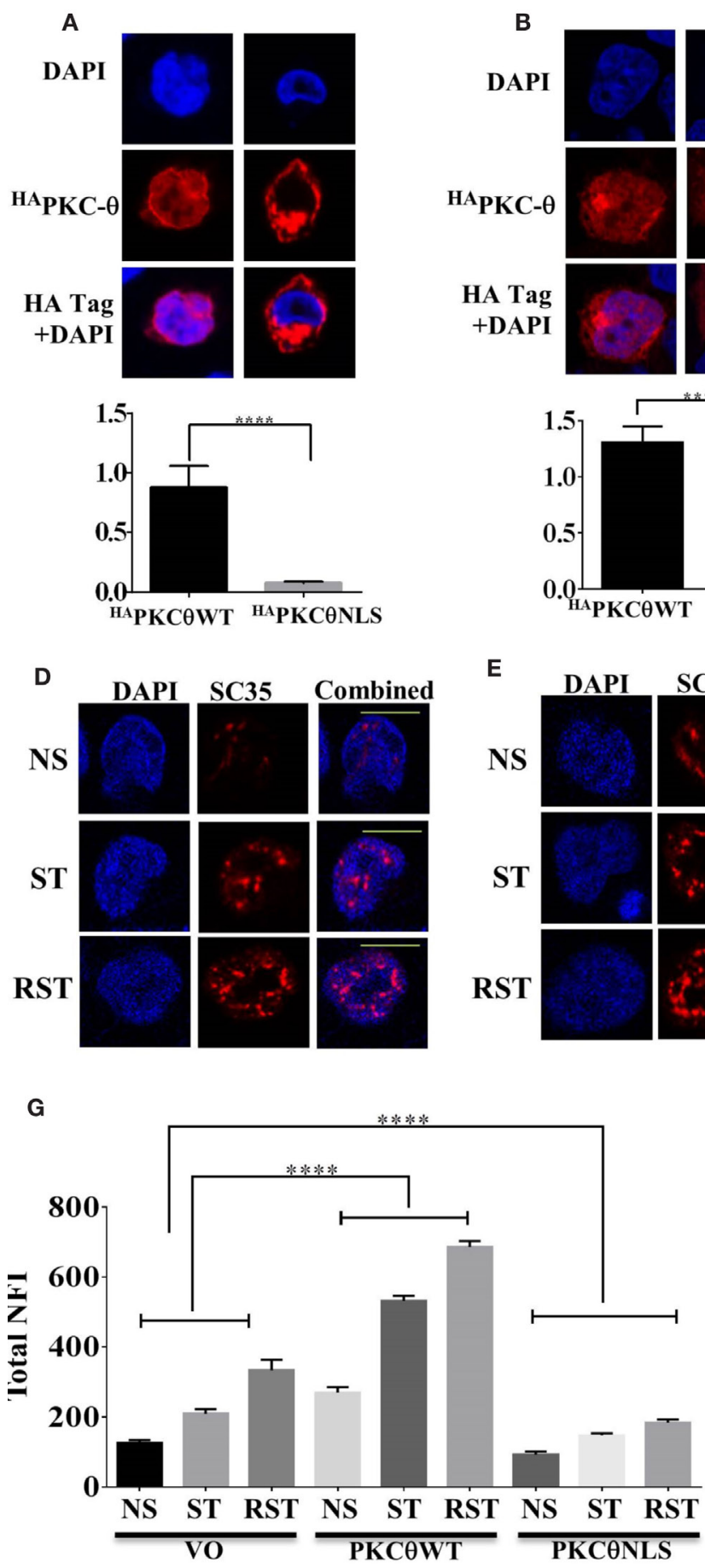

A 1 ag + DAPI
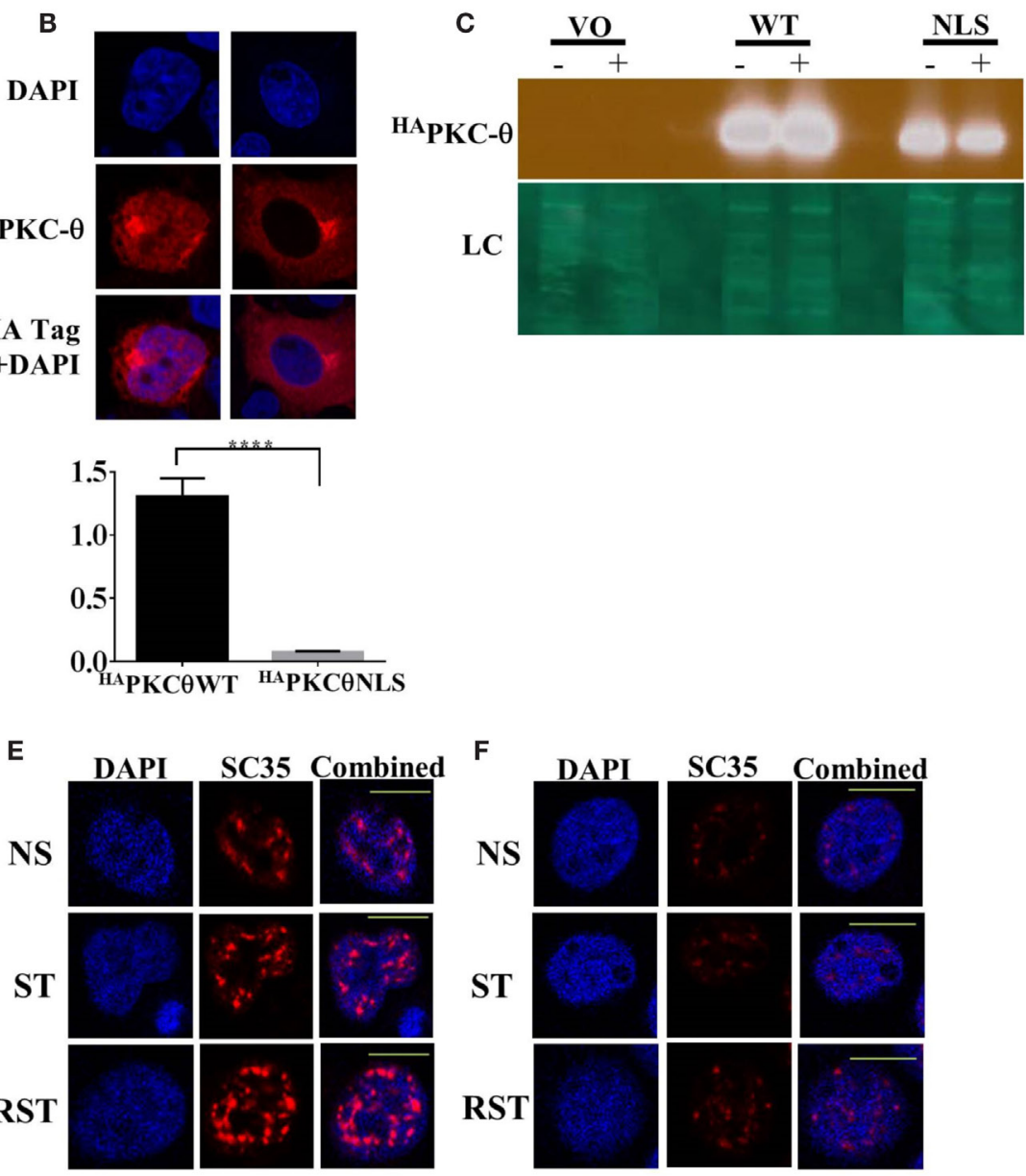

H
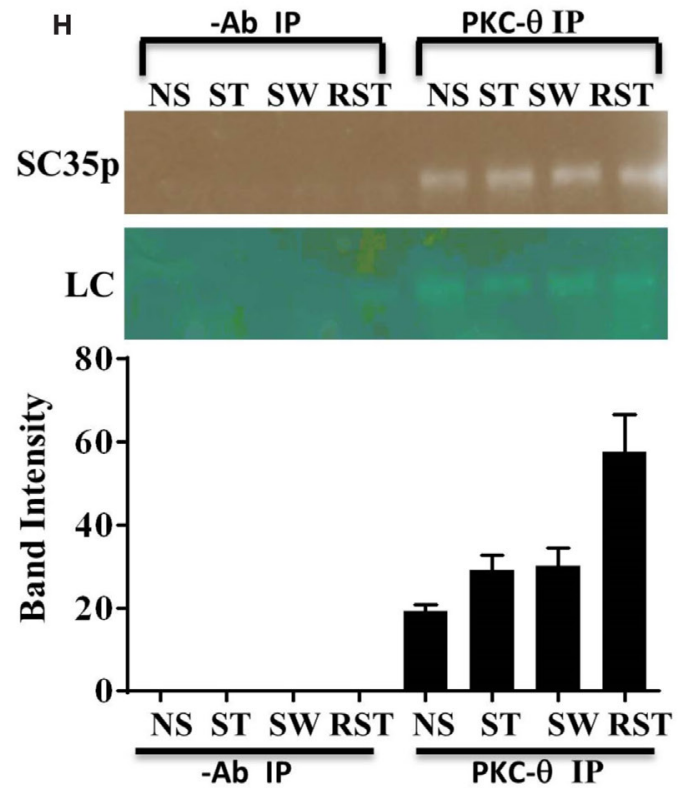

FIGURE 4 | Localization of PKC- $\theta$ in T cells and effect on SC35p 


\section{FIGURE 4 | Continued}

The full-length PKC- $\theta$ wild-type gene sequence ( ${ }^{H A P K C}-\theta$ WT) and the NLS mutation (HAPKC- $\theta$ NLS) were cloned into the pTracer-CMV vector in frame with a C-terminal HA tag. Transfected Hut-78 T cells (A) and Jurkat T cells (B) and were fixed and probed with a rabbit antibody to the HA-tag followed by visualization with a secondary goat antibody to rabbit immunoglobulins conjugated to Alexa-Fluor 568 . Confocal laser scanning microscopy was also used to assess PKC- $\theta$ localization as described in the section "Materials and Methods." Representative images for each construct are shown. Fn/c values for each construct are shown with significant differences between datasets indicated. Data represent the mean \pm SEM, $n=20$ for each dataset. (C) Jurkat T cells were transfected, stimulated, and nuclear extracts created to examine nuclear localization of the PKC- $\theta$ wild-type and PKC $\theta$ NLS mutant. A representative immunoblot image of nuclear extracts showing HAPKC- $\theta$ localization in the nucleus is shown. Jurkat T cells were transfected as described in the section "Materials and Methods" and subsequently stimulated (NS, non-stimulated; ST, stimulated; RST, re-stimulated). Cells were fixed and probed with a mouse antibody to a phospho-epitope of human SC35 with secondary antibodies to mouse immunoglobulins conjugated to Alexa-Fluor 568. Confocal laser scanning microscopy was used to study SC35p expression in HA

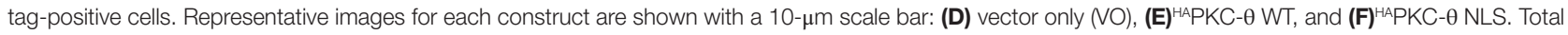
nuclear fluorescence values for each construct are shown with significant differences between datasets indicated (G). Data represent the mean \pm SEM, $n=20$ for each dataset. (H) Nuclear extracts were made from Jurkat T cells stimulated as previously described (NS, no stimulation; ST, stimulation; SW, stimulus withdrawal; RST, re-stimulation) and subjected to half-way CHIP using PKC- $\theta$ pull down or a no antibody control. Samples were probed with a primary mouse antibody to a phospho-epitope of human SC35 as described in the section "Materials and Methods"; representative bands are shown. SC35 band intensity was plotted using Fiji-ImageJ software minus background for $n=3$ with mean \pm SEM.

diminished SC35p in the Jurkat T cells (Figure 4F), as indicated in the nuclear fluorescence data (Figure 4G).

To determine whether nuclear PKC- $\theta$ and SC 35 co-exist in the nucleus in the context of the chromatin template, we performed PKC- $\theta$ half-way ChIP on Jurkat T cell nuclear extracts. Endogenous PKC- $\theta$ and SC35p were associated in Jurkat T cells, particularly in RST Jurkat T cells (Figure 4H). Interestingly, co-existence of both proteins was maintained in SW cells following stimulus withdrawal (Figure $4 \mathbf{H}$ ), but this association increased following secondary stimulation (Figure $\mathbf{4 H}$ ). Taken together, PKC- $\theta$ and SC35p co-exist in the proximity of chromatin within the nuclear compartment of $\mathrm{T}$ cells.

\section{PKC-9 Directly Phosphorylates SC35 at Regulatory Domains}

To determine whether PKC- $\theta$ directly phosphorylates SC35 residues, an in vitro kinase assay was performed in which SC35 peptide constructs were incubated with active PKC- $\theta$ in the presence of radiolabeled $\gamma^{33} \mathrm{P}$-ATP in an array-based format.

Of the 51 peptide constructs tested, 14 were positive for phosphorylation events (Figure 5A). SC35 contains two long stretches of RS repeats and an RRM domain (12). Sequence analysis of these 14 peptides showed that all but two of the positive peptides localized to the long tract dipeptide RS domains (Table 1). In contrast, peptides 5 and 9 localized to the RRM domain at the $\mathrm{N}$-terminal. The peptide with the strongest phosphorylation signal (peptide 1) was located in the RS domain (171AA-186AA; Figure 5B).

We also examined the relationship between phosphorylated peptides and recently identified PKC- $\theta$ motifs (Figure 5C) (46). The strongest peptide signals (peptides 1,2, and 3) contained seven PKC- $\theta$ phosphorylation motifs. Furthermore, the other 11 phosphorylation-positive peptides also contained regions that correlated with putative PKC- $\theta$ phosphorylation motifs. Overall, our data demonstrate that the nuclear PKC- $\theta$ kinase directly phosphorylates SC35 at both RMM and RS regulatory domains.

\section{DISCUSSION}

The contribution of alternative splicing to T cells is an emerging area of immunological research. The interplay between the transcriptional splicing machinery and the chromatin landscape is poorly defined, particularly in T cells. Here, we show that the key splicing factor SC35 is induced in response to T cell stimulatory signals. Specifically, we show that phosphorylated form of SC35 (SC35p) is enriched following T cell activation in Jurkat T cells, human primary $\mathrm{T}$ cells, and ex vivo effector virusspecific $T$ cells isolated after influenza A virus infection. We show that SC35p colocalizes with RNA polymerase II in activated T cells and spatially overlaps with $\mathrm{H} 3 \mathrm{~K} 27 \mathrm{ac}$ and $\mathrm{H} 3 \mathrm{~K} 4 \mathrm{me} 3$, which mark transcriptionally active genes in primary and secondary $\mathrm{T}$ cell activation. PKC- $\theta$ is a novel regulator of SC35 expression in T cells that directly phosphorylates SC35 at its key regulatory regions.

Several PKC family members play a role in mRNA splicing in other cell types $(8,26-28)$. Here, we show that PKC- $\theta$ is a key regulator of SC35 in human T cells, and for the first time demonstrate that nuclear PKC- $\theta$ regulates SC35 phosphorylation in $\mathrm{T}$ cells. The increase in SC35 phosphorylation in PKC- $\theta$ WT-transfected T cells suggests that phosphorylation by PKC- $\theta$ initiates speckle formation and an increase in SC35p signal and concentration. Interestingly, DAG kinase has also been shown to localize in the nucleus (47), and it would be interesting to know whether it is located in a similar active transcription complex as PKC- $\theta$ in T cells. In addition, PIPKs, part of a PKC co-factor pathway, associate with nuclear speckles, further suggesting that PKCs and PKC co-factors play a role in splicing (48).

We demonstrate that PKC- $\theta$ directly phosphorylates SC35 at RS and RRM domains. Furthermore, our data with a PKC catalytic inhibitor and siRNA knockdown suggests that PKC- $\theta$ is critical for SC35 phosphorylation in T cells. The RS domain mediates protein-protein interactions, such as subcellular localization (49), nuclear export, and retention signals (12), and functions as a splicing activator (50). We also identified two PKC- $\theta$-phosphorylated peptides that lie in the RRM domain. The RRM domain recognizes RNA recognition sequencing and has been shown to mediate subcellular localization (49) and alternative splicing specificity $(51,52)$. Future studies will be required to address the essential nature of these novel PKC- $\theta$-targeted phosphorylation sites within key SC35 domains in T cells. It has been reported that Tip60 acetylation of SC35 at lysine residue 52 promotes proteasomal degradation of splicing factors and reduces SC35 phosphorylation (53). Given that Lysine 52 is in 


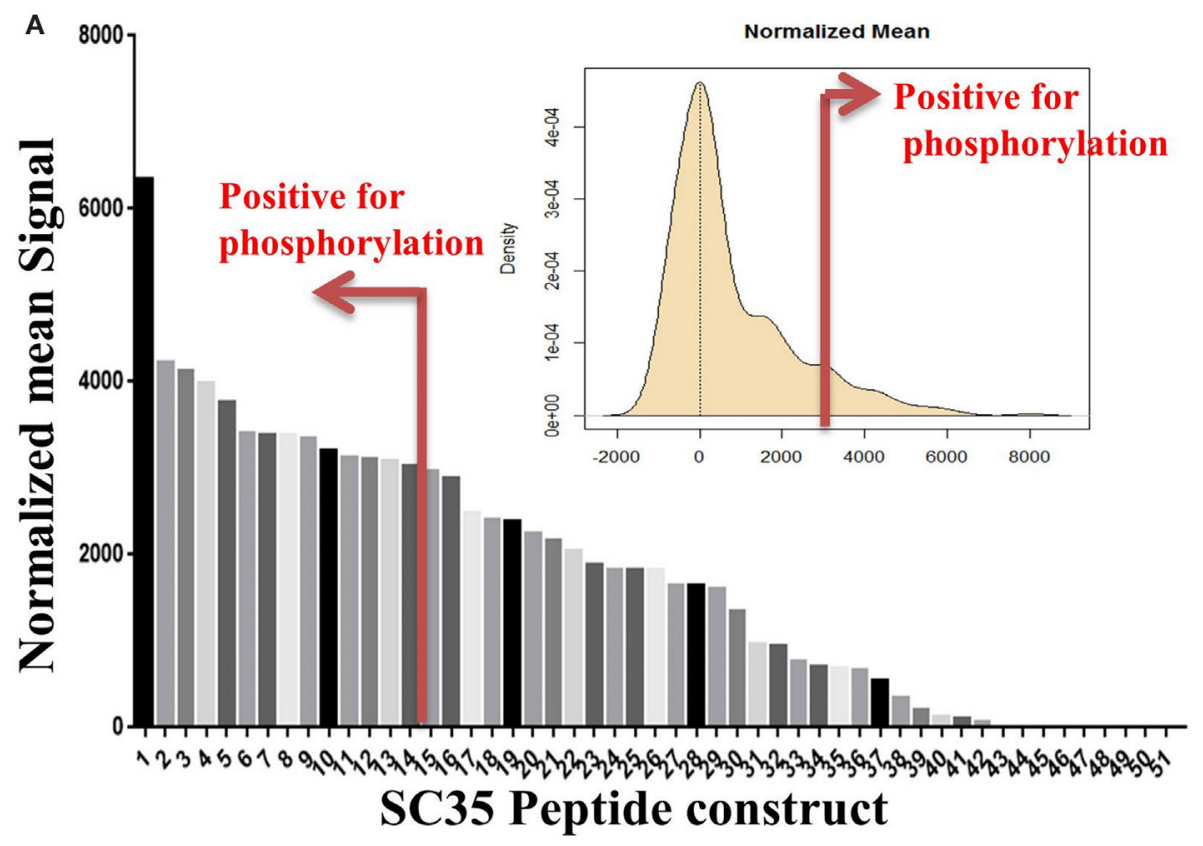

B

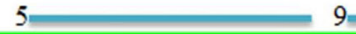

MSYGRPPPDVEGMTSLKVDNLTYRTSPDTLRRVFEKYGRVGDVYIPRDRYTKESRGFAFVRFH 1

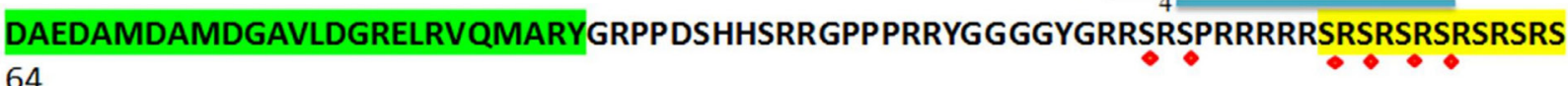
64

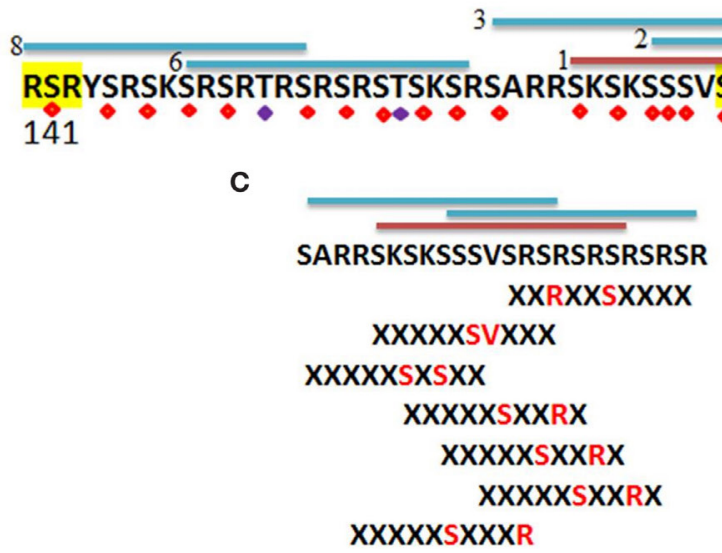

FIGURE 5 | Identification of phosphorylated residues on the SC35 splicing protein. (A) Mean peptide signal and all SC35 peptide constructs used to examine SC35 for phosphorylation by PKC- $\theta$. The red bar indicates the cut-off for positive signal for phosphorylation. The distribution curve for SC35 peptide phosphorylation is also displayed: the $y$-axis is the kernel density estimate of the normalized phosphorylation signal intensities on the $x$-axis, with anything equal to or greater than the red bar ( $2 \times$ SD above the mean) considered a positive phosphorylation event. (B) The amino acid sequence of SC35 indicating the location of the top nine peptides in descending order and their location; the other five peptides correspond to overlaps with the first nine peptide locations. Green highlight denotes the RRM domain, the yellow highlight denotes RS dipeptide repeats. Peptides are numbered in order of mean signal intensity: red bar is the highest signal, blue bars are the other positive SC35 peptides, and possible serine or threonine phosphorylation residues are indicated by red or blue diamonds. (C) The top three peptide sequences and their overlap with the SC35 amino acid sequence. Hutti et al. (46) reported a serine/threonine specific motif for PKC- $\theta$-mediated phosphorylation; using this information, the section of SC35 that scored the top three hits for peptide phosphorylation signals was analyzed for these motifs. Seven separate phosphorylation motifs were identified. 
TABLE 1 | Mean peptide signals and protein domains, related to Figure 6.

\begin{tabular}{llccl}
\hline & $\begin{array}{l}\text { SC35 peptide } \\
\text { sequence }\end{array}$ & Mean & $\begin{array}{l}\text { Normalized } \\
\text { mean }\end{array}$ & $\begin{array}{l}\text { SC35 protein } \\
\text { domain }\end{array}$ \\
\hline Peptide 1 & SKSKSSSVSRSRSRS & 55,706 & 6,331 & RS domain \\
Peptide 2 & SSSVSRSRSRSRSRS & 53,589 & 4,214 & RS domain \\
Peptide 3 & SARRSKSKSSSVSRS & 53,504 & 4,129 & RS domain \\
Peptide 4 & SPRRRRRSRSRSRSR & 53,345 & 3,970 & RS domain \\
Peptide 5 & LTYRTSPDTLRRVFE & 53,132 & 3,757 & RRM domain \\
Peptide 6 & SRSRTRSRSRSTSKS & 52,781 & 3,406 & RS domain \\
Peptide 7 & RRSRSPRRRRRSRSR & 52,746 & 3,370 & RS domain \\
Peptide 8 & RSRYSRSKSRSRTRS & 52,745 & 3,370 & RS domain \\
Peptide 9 & YGRVGDVYPRDRYT & 52,722 & 3,346 & RRM domain \\
Peptide 10 & PPVSKRESKSRSRSK & 52,575 & 3,199 & RS domain \\
Peptide 11 & SRSKSRSRTRSRSRS & 52,497 & 3,121 & RS domain \\
Peptide 12 & SRSTSKSRSARRSKS & 52,475 & 3,100 & RS domain \\
Peptide 13 & SKSRSARRSKSKSSS & 52,461 & 3,086 & RS domain \\
Peptide 14 & SRSRSRSRSRSPPPV & 52,402 & 3,026 & RS domain \\
\hline
\end{tabular}

The mean peptide signals for all 14 SC35 peptide constructs above the positive cut-off for phosphorylation. The peptide sequence and the protein domain occupied are also tabulated. proximity to putative PKC- $\theta$ phosphorylation sites in the RRM domain, and siRNA and rottlerin inhibitor experiments implicate PKC- $\theta$ kinase activity in SC35 RRM domain phosphorylation, an intriguing possibility exists that this phosphorylation by PKC$\theta$ may play a role in preserving the SC35 nuclear speckle from degradation in T cells.

Memory $\mathrm{T}$ cells elicit fast and enhanced secondary immune responses upon antigen exposure to mount effective adaptive immune responses to infectious diseases and cancers (54-56). Enhanced memory $\mathrm{T}$ cell function is underpinned by the rapid induction of a distinct cohort of genes in response to antigenic re-challenge (57-59). This transcriptional response is greater and more robust in memory than naïve $T$ cells. Furthermore, memory T cells "remember" previous transcriptional responses for decades in humans in the absence of antigen (60). Although the rapid recall responses of memory $\mathrm{T}$ cells are well documented, the signaling pathways and mechanisms that regulate $\mathrm{T}$ cell transcriptional

Naïve T-Cells/Nonstimulated

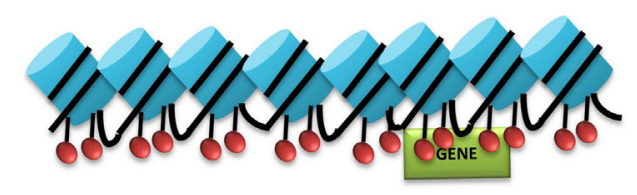

Effector T-Cells/ Stimulated
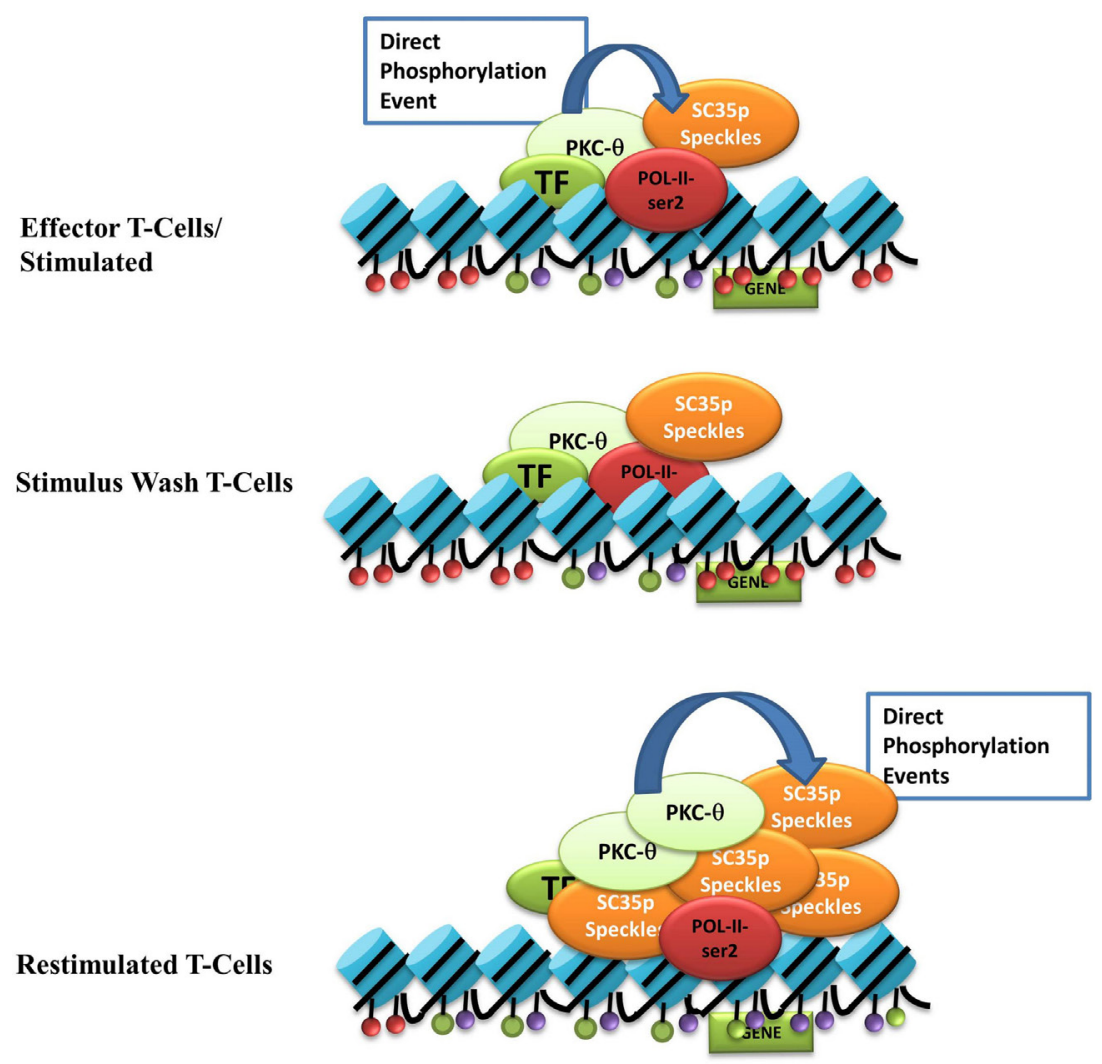

FIGURE 6 | Nuclear PKC- $\theta$ as a novel regulator of SC35 in T-cells. Our model of the interaction between PKC- $\theta$ and SC35 in the context of TM in Jurkat T cells. Blue cylinders represent histones, and the colored ovals represent histone PTMs: red = repressive, purple (H3k27ac), or green (H3k4me3). Light green oval is PKC- $\theta$, red oval is RNA-Pol-II, the darker green oval represents various TFs, and the orange oval is SC35p speckles. Upon stimulation, PKC- $\theta$ enters the nucleus and binds to a chromatin platform incorporating RNA-PoI-II and various transcription factors. At the same time, PKC- $\theta$ phosphorylates SC35, relocating the speckle to the site of transcription to potentially form a linked complex between the chromatin platform, the splicing speckle, and active histone marks. After stimulus withdrawal, this association between PKC- $\theta /$ TFs, histone PTMs, and SC35 speckles is maintained and expands even further upon re-stimulation to effect massive recruitment of phosphorylated SC35 splicing speckles. 
memory are complex and have yet to be fully elucidated (61-63). We show in this study that SC35p colocalizes with RNA Pol II and key histone marks in primary and secondary-activated $\mathrm{T}$ cells. An interesting finding was that SC35p remained closely associated with key histone marks in SW Jurkat T cells in spite of the absence of activating signals. Furthermore, SC35p and PKC- $\theta$ co-existed in close proximity to the chromatin platform following stimulus withdrawal. The maintenance of SC35 in SW Jurkat T cells suggests that SC35 exists in a poised or ready state following stimulus withdrawal. This poised state may serve as a transcriptional memory signature that marks genes for rapid transcription upon secondary activation. We show that SC35 colocalizes with active histone marks $\mathrm{H} 3 \mathrm{~K} 27 \mathrm{ac}$ and $\mathrm{H} 3 \mathrm{~K} 4 \mathrm{me} 3$; however, while $\mathrm{H} 3 \mathrm{~K} 27 \mathrm{ac}$ marks active enhancers, $\mathrm{H} 3 \mathrm{~K} 4 \mathrm{me} 3$ is largely deposited at promoter regions $(45,64)$. Given that $\mathrm{H} 3 \mathrm{~K} 4 \mathrm{me} 3$ is increased in memory T cells and in effector cells at active gene loci (65), the role of SC35 at gene enhancers in memory T cells deserves further study. Since SC35 is also implicated in chromatin remodeling (66), proteomic analysis will be required to explore the interplay between the enzymes that regulate T cell memory and SC35 in T cells.

We propose a model in which nuclear PKC- $\theta$ interacts with SC35 in distinct $\mathrm{T}$ cell activation states (see Figure 6). Upon stimulation, nuclear PKC- $\theta$ forms an active transcription complex with RNA Pol II as previously described (31). At the same time, PKC- $\theta$ directly phosphorylates SC35 speckles at RS and RRM domains to direct localization of SC35p near active gene expression regions, such as H3K27ac-marked enhancers, and initiates speckle formation. Following stimulus removal, the SC35p speckle and PKC- $\theta$ complex are maintained in a poised or ready state near accessible chromatin. Reactivation signals increase SC35p and further induce phosphorylation of SC35p speckles. Together, future studies will be required to provide

\section{REFERENCES}

1. Nilsen TW, Graveley BR. Expansion of the eukaryotic proteome by alternative splicing. Nature (2010) 463(7280):457-63. doi:10.1038/nature08909

2. Will CL, Luhrmann R. Spliceosome structure and function. Cold Spring Harb Perspect Biol (2010) 3(7):a003707. doi:10.1101/cshperspect.a003707

3. Spector DL, Lamond AI. Nuclear speckles. Cold Spring Harb Perspect Biol (2010) 3(2):a000646. doi:10.1101/cshperspect.a000646

4. Chen M, Manley JL. Mechanisms of alternative splicing regulation: insights from molecular and genomics approaches. Nat Rev Mol Cell Biol (2009) 10(11):741-54. doi:10.1038/nrm2777

5. Lynch KW. Consequences of regulated pre-mRNA splicing in the immune system. Nat Rev Immunol (2004) 4(12):931-40. doi:10.1038/nri1497

6. Martinez NM, Lynch KW. Control of alternative splicing in immune responses: many regulators, many predictions, much still to learn. Immunol Rev (2013) 253(1):216-36. doi:10.1111/imr.12047

7. Matter N, Herrlich P, König H. Signal-dependent regulation of splicing via phosphorylation of Sam68. Nature (2002) 420(6916):691-5. doi:10.1038/nature01153

8. Lynch KW, Weiss A. A model system for activation-induced alternative splicing of CD45 pre-mRNA in T cells implicates protein kinase C and Ras. Mol Cell Biol (2000) 20(1):70-80. doi:10.1128/MCB.20.1.70-80.2000

9. Arch R, Wirth K, Hofmann M, Ponta H, Matzku S, Herrlich P, et al. Participation in normal immune responses of a metastasis-inducing splice variant of CD44. Science (1992) 257(5070):682-5. doi:10.1126/science.1496383

10. Ip JY, Tong A, Pan Q, Topp JD, Blencowe BJ, Lynch KW. Global analysis of alternative splicing during T-cell activation. RNA (2007) 13(4):563-72. doi:10.1261/rna.457207 in-depth mechanistic insights into the contribution of SC35p in marking genes for rapid reactivation.

Given that PKC- $\theta$ regulates the key splicing factor SC35, future studies should aim to address the role of PKC- $\theta$ in alternative splicing utilizing global, high-throughput methods, such as RNA sequencing. It will also be important to determine if nuclear kinase-regulated splicing is unique to $\mathrm{T}$ cells or whether other kinases, such as Akt and CDK5/p35, which mediate $\mathrm{CD}^{+} \mathrm{T}$ cell differentiation and neuronal development, play a nuclear role in splicing. Unraveling the role of alternative splicing in $\mathrm{T}$ cell regulation is likely to be useful in translational applications in autoimmune diseases and cancer biology.

\section{AUTHOR CONTRIBUTIONS}

RM conducted the experiments for Figures 1-4, carried out the analysis, and wrote parts of the paper; JD conducted the experiment for Figure 3C with RM and wrote the paper with SR; JL prepared virus-specific T cells; AM, TK, MS, and JZ conducted the experiments for Figure 5. SR: proposed the concept, helped with analysis, and wrote the paper.

\section{ACKNOWLEDGMENTS}

This work was supported by NHMRC Project Grant (APP1025718) awarded to SR, the ESTeM Faculty (CReSTS) Stipend Scholarship awarded to JD, and the Australian Post-Graduate award (APA) awarded to RM in SR's laboratory.

\section{SUPPLEMENTARY MATERIAL}

The Supplementary Material for this article can be found online at http://journal.frontiersin.org/article/10.3389/fimmu.2015.00562

11. Martinez NM, Pan Q, Cole BS, Yarosh CA, Babcock GA, Heyd F, et al. Alternative splicing networks regulated by signaling in human $\mathrm{T}$ cells. RNA (2012) 18(5):1029-40. doi:10.1261/rna.032243.112

12. Cazalla D, Zhu J, Manche L, Huber E, Krainer AR, Caceres JF. Nuclear export and retention signals in the RS domain of SR proteins. Mol Cell Biol (2002) 22(19):6871-82. doi:10.1128/MCB.22.19.6871-6882.2002

13. Lin S, Coutinho-Mansfield G, Wang D, Pandit S, Fu X-D. The splicing factor SC35 has an active role in transcriptional elongation. Nat Struct Mol Biol (2008) 15(8):819-26. doi:10.1038/nsmb.1394

14. Zhong X-Y, Wang P, Han J, Rosenfeld MG, Fu X-D. SR proteins in vertical integration of gene expression from transcription to RNA processing to translation. Mol Cell (2009) 35(1):1-10. doi:10.1016/j.molcel.2009.06.016

15. Liu HX, Chew SL, Cartegni L, Zhang MQ, Krainer AR. Exonic Splicing enhancer motif recognized by human SC35 under splicing conditions. Mol Cell Biol (2000) 20(3):1063-71. doi:10.1128/MCB.20.16.6105-6113.2000

16. Wang H-Y, Xu X, Ding J-H, Bermingham JR, Fu X-D. SC35 plays a role in T cell development and alternative splicing of CD45. Mol Cell (2001) 7(2):331-42. doi:10.1016/S1097-2765(01)00229-5

17. Loh TJ, Moon H, Cho S, Jung D-W, Hong S-E, Kim DH, et al. SC35 promotes splicing of the C5-V6-C6 isoform of CD44 pre-mRNA. Oncol Rep (2013) 31(1):273-79. doi:10.3892/or.2013.2812

18. Makishima H, Visconte V, Sakaguchi H, Jankowska AM, Abu Kar S, Jerez A, et al. Mutations in the spliceosome machinery, a novel and ubiquitous pathway in leukemogenesis. Blood (2012) 119(14):3203-10. doi:10.1182/ blood-2011-12-399774

19. Moulton VR, Grammatikos AP, Fitzgerald LM, Tsokos GC. Splicing factor SF2/ASF rescues IL-2 production in T cells from systemic lupus erythematosus 
patients by activating IL-2 transcription. Proc Natl Acad Sci U S A (2013) 110(5):1845-50. doi:10.1073/pnas.1214207110

20. Maldarelli F, Xiang C, Chamoun G, Zeichner SL. The expression of the essential nuclear splicing factor SC35 is altered by human immunodeficiency virus infection. Virus Res (1998) 53(1):39-51. doi:10.1016/S0168-1702(97)00130-5

21. Moon H, Cho S, Loh TJ, Oh HK, Jang HN, Zhou J, et al. SRSF2 promotes splicing and transcription of exon 11 included isoform in Ron proto-oncogene. Biochim Biophys Acta (2014) 1839(11):1132-40. doi:10.1016/j. bbagrm.2014.09.003

22. McFarlane M, MacDonald AI, Stevenson A, Graham SV. Human papillomavirus 16 oncoprotein expression is controlled by the cellular splicing factor SRSF2 (SC35). J Virol (2015) 89(10):5276-87. doi:10.1128/JVI.03434-14

23. Qian W, Liang H, Shi J, Jin N, Grundke-Iqbal I, Iqbal K, et al. Regulation of the alternative splicing of tau exon 10 by SC35 and Dyrk1A. Nucleic Acids Res (2011) 39(14):6161-71. doi:10.1093/nar/gkr195

24. Colwill K, Pawson T, Andrews B, Prasad J, Manley JL, Bell JC, et al. The Clk/ Sty protein kinase phosphorylates SR splicing factors and regulates their intranuclear distribution. EMBO J (1996) 15(2):265-75.

25. Prasad J, Manley JL. Regulation and substrate specificity of the SR protein kinase Clk/Sty. Mol Cell Biol (2003) 23(12):4139-49. doi:10.1128/MCB.23.12. 4139-4149.2003

26. Revil T, Toutant J, Shkreta L, Garneau D, Cloutier P, Chabot B. Protein kinase C-dependent control of Bcl-x alternative splicing. Mol Cell Biol (2007) 27(24):8431-41. doi:10.1128/MCB.00565-07

27. Cataldi A, Zingariello M, Rapino M, Zara S, Daniele F, Di Giulio C, et al. Effect of hypoxia and aging on PKC $\delta$-mediated SC-35 phosphorylation in rat myocardial tissue. Anat Rec (Hoboken) (2009) 292(8):1135-42. doi:10.1002/ar.20936

28. Zara S, Bosco D, Di Giulio C, Antonucci A, Cataldi A. Protein kinase Calpha early activates splicing factor SC-35 during post-natal rat heart development. J Biol Regul Homeost Agents (2009) 23(1):45-54.

29. Isakov N, Altman A. Protein kinase $\mathrm{C} \theta$ in T cell activation. Annu Rev Immunol (2002) 20(1):761-94. doi:10.1146/annurev.immunol.20.100301.064807

30. Hayashi K, Altman A. Protein kinase C theta (PKC $)$ ): a key player in T cell life and death. Pharmacol Res (2007) 55(6):537-44. doi:10.1016/j.phrs.2007.04.009

31. Sutcliffe EL, Bunting KL, He YQ, Li J, Phetsouphanh C, Seddiki N, et al. Chromatin-associated protein kinase C- $\theta$ Regulates an inducible gene expression program and microRNAs in human T lymphocytes. Mol Cell (2011) 41(6):704-19. doi:10.1016/j.molcel.2011.02.030

32. Rao S, Procko E, Shannon MF. Chromatin remodeling, measured by a novel real-time polymerase chain reaction assay, across the proximal promoter region of the IL-2 gene. J Immunol (2001) 167(8):4494-503. doi:10.4049/ jimmunol.167.8.4494

33. Springael C, Thomas S, Rahmouni S, Vandamme A, Goldman M, Willems F, et al. Rottlerin inhibits human T cell responses. Biochem Pharmacol (2007) 73(4):515-25. doi:10.1016/j.bcp.2006.10.034

34. Sutcliffe EL, Li J, Zafar A, Hardy K, Ghildyal R, McCuaig R, et al. Chromatinized protein kinase C- $\theta$ : can it escape the clutches of NF- $\kappa B$ ? Front Immunol (2012) 3:260. doi:10.3389/fimmu.2012.00260

35. Ghildyal R, Ho A, Dias M, Soegiyono L, Bardin PG, Tran KC, et al. The respiratory syncytial virus matrix protein possesses a Crm1-mediated nuclear export mechanism. J Virol (2009) 83(11):5353-62. doi:10.1128/JVI.01748-08

36. Schindelin J, Arganda-Carreras I, Frise E, Kaynig V, Longair M, Pietzsch T, et al. Fiji: an open-source platform for biological-image analysis. Nat Methods (2012) 9(7):676-82. doi:10.1038/nmeth.2019

37. Bolte S, Cordelieres FP. A guided tour into subcellular colocalization analysis in light microscopy. J Microsc (2006) 224(Pt 3):213-32. doi:10.1111/j.1365-2818.2006.01706.x

38. Adler J, Parmryd I. Quantifying colocalization by correlation: the Pearson correlation coefficient is superior to the Mander's overlap coefficient. Cytometry A (2010) 77(8):733-42. doi:10.1002/cyto.a.20896

39. Sutcliffe EL, Parish IA, He YQ, Juelich T, Tierney ML, Rangasamy D, et al. Dynamic histone variant exchange accompanies gene induction in T cells. Mol Cell Biol (2009) 29(7):1972-86. doi:10.1128/MCB.01590-08

40. Jenkins MR, Webby R, Doherty PC, Turner SJ. Addition of a prominent epitope affects influenza A virus-specific CD8+ T cell immunodominance hierarchies when antigen is limiting. JImmunol (2006) 177(5):2917-25. doi:10.4049/jimmunol.177.5.2917

41. Kouzarides T. Chromatin modifications and their function. Cell (2007) 128(4):693-705. doi:10.1016/j.cell.2007.02.005
42. Li B, Carey M, Workman JL. The role of chromatin during transcription. Cell (2007) 128(4):707-19. doi:10.1016/j.cell.2007.01.015

43. Strahl $\mathrm{BD}$, Allis $\mathrm{CD}$. The language of covalent histone modifications. Nature (2000) 403(6765):41-5. doi:10.1038/47412

44. Bernstein BE, Mikkelsen TS, Xie X, Kamal M, Huebert DJ, Cuff J, et al. A bivalent chromatin structure marks key developmental genes in embryonic stem cells. Cell (2006) 125(2):315-26. doi:10.1016/j.cell.2006.02.041

45. Creyghton MP, Cheng AW, Welstead GG, Kooistra T, Carey BW, Steine EJ, et al. Histone H3K27ac separates active from poised enhancers and predicts developmental state. Proc Natl Acad Sci U S A (2010) 107(50):21931-6. doi:10.1073/pnas.1016071107

46. Hutti JE, Jarrell ET, Chang JD, Abbott DW, Storz P, Toker A, et al. A rapid method for determining protein kinase phosphorylation specificity. Nat Methods (2004) 1(1):27-9. doi:10.1038/nmeth708

47. Tabellini G, Bortul R, Santi S, Riccio M, Baldini G, Cappellini A, et al. Diacylglycerol kinase- $\theta$ is localized in the speckle domains of the nucleus. Exp Cell Res (2003) 287(1):143-54. doi:10.1016/S0014-4827(03)00115-0

48. Boronenkov IV, Loijens JC, Umeda M, Anderson RA. Phosphoinositide signaling pathways in nuclei are associated with nuclear speckles containing premRNA processing factors. Mol Biol Cell (1998) 9(12):3547-60. doi:10.1091/ mbc.9.12.3547

49. Kavanagh SJ, Schulz TC, Davey P, Claudianos C, Russell C, Rathjen PD. A family of RS domain proteins with novel subcellular localization and trafficking. Nucleic Acids Res (2005) 33(4):1309-22. doi:10.1093/nar/gki269

50. Graveley BR, Maniatis T. Arginine/serine-rich domains of SR proteins can function as activators of pre-mRNA splicing. Mol Cell (1998) 1(5):765-71. doi:10.1016/S1097-2765(00)80076-3

51. Chandler SD, Mayeda A, Yeakley JM, Krainer AR, Fu XD. RNA splicing specificity determined by the coordinated action of RNA recognition motifs in SR proteins. Proc Natl Acad Sci U S A (1997) 94(8):3596-601. doi:10.1073/ pnas.94.8.3596

52. Caceres JF, Misteli T, Screaton GR, Spector DL, Krainer AR. Role of the modular domains of SR proteins in subnuclear localization and alternative splicing specificity. J Cell Biol (1997) 138(2):225-38. doi:10.1083/jcb.138.2.225

53. Edmond V, Moysan E, Khochbin S, Matthias P, Brambilla C, Brambilla E, et al. Acetylation and phosphorylation of SRSF 2 control cell fate decision in response to cisplatin. EMBO J (2011) 30(3):510-23. doi:10.1038/emboj.2010.333

54. Wherry EJ, Ahmed R. Memory CD8 T-cell differentiation during viral infection. J Virol (2004) 78(11):5535-45. doi:10.1128/JVI.78.11.5535-5545.2004

55. Swain SL, McKinstry KK, Strutt TM. Expanding roles for CD4+ T cells in immunity to viruses. Nat Rev Immunol (2012) 12(2):136-48. doi:10.1038/ nri3152

56. Sharma RK, Yolcu ES, Srivastava AK, Shirwan H. CD4+ T cells play a critical role in the generation of primary and memory antitumor immune responses elicited by SA-4-1BBL and TAA-based vaccines in mouse tumor models. PLoS One (2013) 8(9):e73145. doi:10.1371/ annotation/8aaa2a9c-9c15-4214-808d-db8b0bd8ab88

57. Zimmermann C, Prévost-Blondel A, Blaser C, Pircher H. Kinetics of the response of naive and memory $\mathrm{CD} 8 \mathrm{~T}$ cells to antigen: similarities and differences. Eur JImmunol (1999) 29(1):284-90. doi:10.1002/ (SICI) 1521-4141(199901)29:01<284::AID-IMMU284>3.0.CO;2-C

58. Rogers PR, Dubey C, Swain SL. Qualitative changes accompany memory $\mathrm{T}$ cell generation: faster, more effective responses at lower doses of antigen. J Immunol (2000) 164(5):2338-46. doi:10.4049/jimmunol.164.6.2955

59. Veiga-Fernandes H, Walter U, Bourgeois C, McLean A, Rocha B. Response of naive and memory CD8+ T cells to antigen stimulation in vivo. Nat Immunol (2000) 1(1):47-53. doi:10.1038/76907

60. Hammarlund E, Lewis MW, Hansen SG, Strelow LI, Nelson JA, Sexton GJ, et al. Duration of antiviral immunity after smallpox vaccination. Nat Med (2003) 9(9):1131-7. doi:10.1038/nm917

61. Weng N-P, Araki Y, Subedi K. The molecular basis of the memory T cell response: differential gene expression and its epigenetic regulation. Nat Rev Immunol (2012) 12(4):306-15. doi:10.1038/nri3173

62. Thaventhiran JED, Fearon DT, Gattinoni L. Transcriptional regulation of effector and memory CD8+ T cell fates. Curr Opin Immunol (2013) 25(3):321-8. doi:10.1016/j.coi.2013.05.010

63. Dunn J, McCuaig R, Tu WJ, Hardy K, Rao S. Multi-layered epigenetic mechanisms contribute to transcriptional memory in T lymphocytes. BMC Immunol (2015) 16(1):27. doi:10.1186/s12865-015-0089-9 
64. Guenther MG, Levine SS, Boyer LA, Jaenisch R, Young RA. A chromatin landmark and transcription initiation at most promoters in human cells. Cell (2007) 130(1):77-88. doi:10.1016/j.cell.2007.05.042

65. Araki Y, Wang Z, Zang C, Wood WH, Schones D, Cui K, et al. Genome-wide analysis of histone methylation reveals chromatin state-based regulation of gene transcription and function of memory CD8+ T cells. Immunity (2009) 30(6):912-25. doi:10.1016/j.immuni.2009.05.006

66. Pradeepa MM, Sutherland HG, Ule J, Grimes GR, Bickmore WA. Psip1/Ledgf p52 binds methylated histone H3K36 and splicing factors and contributes to the regulation of alternative splicing. PLoS Genet (2012) 8(5):e1002717. doi:10.1371/journal.pgen.1002717
Conflict of Interest Statement: The authors declare that the research was conducted in the absence of any commercial or financial relationships that could be construed as a potential conflict of interest.

Copyright (C) 2015 McCuaig, Dunn, Li, Masch, Knaute, Schutkowski, Zerweck and Rao. This is an open-access article distributed under the terms of the Creative Commons Attribution License (CC BY). The use, distribution or reproduction in other forums is permitted, provided the original author(s) or licensor are credited and that the original publication in this journal is cited, in accordance with accepted academic practice. No use, distribution or reproduction is permitted which does not comply with these terms. 